\title{
Measured and predicted fluxes of biogenic silica in Lake Michigan ${ }^{1}$
}

\author{
Claire L. Schelske
}

Great Lakes Research Division, University of Michigan, Ann Arbor 48109

Brian J. Eadie

Great Lakes Environmental Research Laboratory, NOAA, Ann Arbor, Michigan 48104

Gerald L. Krausse

Great Lakes Research Division, University of Michigan

\begin{abstract}
Diatom production in the offshore waters of Lake Michigan is limited by silica supplies in late summer and can be predicted from the seasonal disappearance of silica from the trophogenic zone. Biogenic silica fluxes obtained from sediment trap collections were compared with fluxes predicted from the silica disappearance model. Measured and predicted fluxes were in good agreement for offshore stations, but at stations closer to shore measured fluxes were 2-3 times greater than predicted fluxes. Sediment trap and water chemistry data show that little of the diatom production is dissolved in the water column. Therefore, greater than predicted fluxes at nearshore locations were attributed to new silica supplied from upwellings, tributary inputs, and recycling and resuspension in nearshore sediments. The good agreement betwcen measured and predicted fluxes in offshore waters shows that biogenic silica fluxes may be useful in determining the collecting efficiency of scdiment traps.
\end{abstract}

Lake Michigan provides an ideal system for the study of seasonal dynamics of the silica cycle. The annual seasonal change in concentration of soluble silica is $1.3 \mathrm{mg}$. liter $^{-1}$ (Rousar 1973)-the largest seasonal disappearance among the five Laurentian Great Lakes (Schelske et al. 1983). Lake Huron and Lake Superior have larger concentrations of soluble silica than Lake Michigan but, because phosphorus concentrations are lower, there is less silica disappearance or diatom production than in Lake Michigan. Because of excessive phosphorus inputs, epilimnetic diatom production in Lake Michigan is limited by available supplies of silica during summer stratification (Schelske and Stoermer 1971). The supply of silica for diatom growth is maintained mainly by recycling (dissolution) of biogenic silica (Conway et al. 1977), with $<5 \%$ of the silica required annually for diatom production being supplied from tributary inputs (Parker et al. 1977). Only one paper has been

${ }^{1}$ This is Contribution 356, Great Lakes Research Division (University of Michigan), and Contribution 320, Great Lakes Environmental Research Laboratory (NOAA). The research was supported in part on U.S. EPA grants R-806294 and R-804503 to C.L.S. published on biogenic silica fluxes obtained from sediment trap collections in the Great Lakes (Parker et al. 1977). Silica disappearance resulting from biological processes has been studied indirectly in several marine and coastal systems (see Paasche and Ostergren 1980). However, according to Paasche and Ostergren (1980), there are few quantitative data on the subsequent fate of silica in the water column, due to the lack of an analytical method for biogenic silica in seawater.

We present here data on biogenic silica fluxes from two independent types of field experiments and compare these data with predicted fluxes calculated from a silica disappearance model (Schelske 1975). Independent estimates of biogenic silica fluxes were obtained from sediment trap collections and from observed changes in total silica concentrations (soluble plus biogenic) in the trophogenic zone. Measured fluxes from sediment traps agreed well with predicted and calculated fluxes for offshore stations; however, at stations closer to shore and the Grand River, biogenic silica fluxes were 2-3 times greater than predicted by the disappearance model. Our hypothesis is that the increased flux at the nearshore sta- 


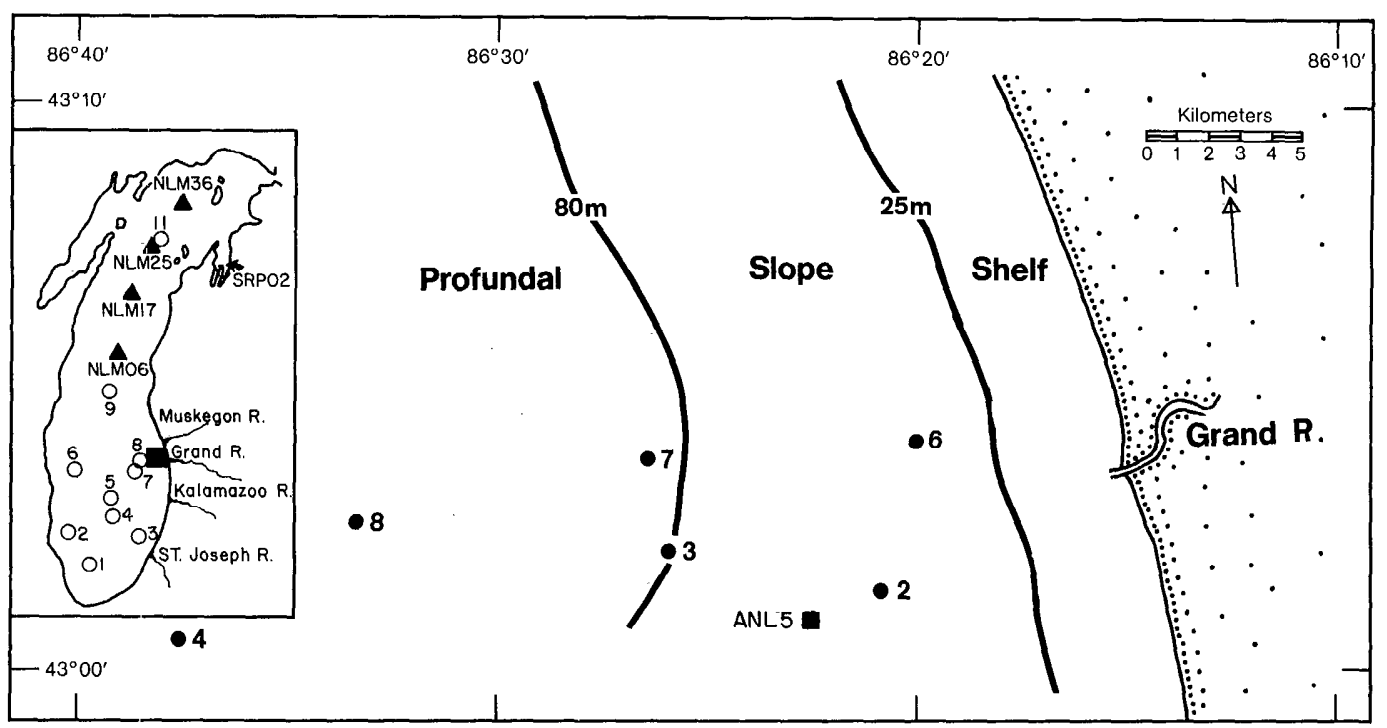

Fig. 1. Station locations. 1976 NLM water chemistry stations-A; 1978 NOAA sediment trap stations-0; 1980-1981 sediment trap stations-O. Other stations (1975 ANL 5 and 1979 SRP 02) are designated by the alphanumeric station code.

tions resulted from a combination of new silica supplied from tributary inputs, upwellings, and sediment release in these shallow waters. New silica is used to denote silica that is supplied from sources other than residual and recycled silica in the euphotic zone. In the sense that this silica is newly available and supplied differently than silica in the offshore waters, it yields "new production" similar to the "new production" from nitrate that was distinguished by Dugdale and Goering (1967) from the "regenerated production" supplied by ammonia. In offshore waters in Lake Michigan, "regenerated silica" is replenished annually to the trophogenic zone only during winter mixing.

Confusing terminology about different forms of silica in waters appears in the literature (Nelson and Gordon 1982). We will use the following terms. Silica or soluble silica: the soluble component which passes through a small porosity filter; this fraction is sometimes termed soluble reactive silica. Biogenic or amorphous silica: silica in living organisms, primarily diatoms and chrysophycean cysts, which can be leached in digestions with strong bases. Particulate silica: biogenic silica plus other solid phases as measured after fusion with carbonate or borate or digestion with hydrofluoric acid. Total silica: the sum of soluble and biogenic silica. Our data on different forms of silica are reported here as mass concentrations of $\mathrm{SiO}_{2}$.

\section{Methods}

Biogenic silica fluxes were calculated directly from the biogenic silica content of sediment trap samples collected in 1978 and 1980-1981 and indirectly from measurements of soluble and biogenic or particulate silica in the water column in 1975, 1976, and 1979. Stations are shown in Fig. 1.

Sediment traps-Sediment traps consisted of Plexiglas cylinders $(50 \times 10 \mathrm{~cm})$ with a powder funnel and widemouth bottle (500 $\mathrm{ml}$, linear polyethylene spiked with $25 \mathrm{ml}$ of chloroform to minimize microbial activity) attached at the bottom to collect sedimented materials (Chambers and Eadie 1981). Including the funnel and collection bottle at the bottom of the trap essentially eliminates fluid exchange between the water in the collection bottle and the trap. The 5:1 height-to-diameter collecting ratio has high (>90\%) collection efficiency (Gardner 
1980a,b; Hargrave and Burns 1979; Wahlgren and Nelson 1976).

To detcrmine biogenic silica, we weighed portions of dried samples from sediment traps (gencrally from $2-5 \mathrm{mg}$ ) and leached them in plastic vials with $30 \mathrm{ml}$ of $1.0 \%$ $\mathrm{Na}_{2} \mathrm{CO}_{3}$ for $2 \mathrm{~h}$ at $85^{\circ} \mathrm{C}$ (DeMaster 1981). Concentration of silica was determined with the heteropoly blue method on a Technicon AutoAnalyzer II system. The concentration (mg $\mathrm{SiO}_{2} \cdot$ liter $^{-1}$ ) multiplied by $30 / 1,000$ gave the weight of biogenic silica in the sample. This weight was divided by the original tared sample weight to obtain the fraction of biogenic silica in the mass flux, which was then multiplied by the daily mass flux rate to obtain the flux of biogenic silica in $\mathrm{g} \mathrm{SiO}_{2} \cdot \mathrm{m}^{-2} \cdot \mathrm{d}^{-1}$. Precision in obtaining the fraction of biogenic silica was excellent; values for duplicate samples deviated $<5 \%$ of the mean.

Calculated fluxes-Indirect estimates of fluxes were calculated from the disappcarance or depletion of total silica from the water column. If we assume that the seasonal disappearance of soluble silica from the water column is the result of uptake and growth of diatoms, then the potential flux of biogenic silica from the euphotic zone is equal to this uptake (Schelske 1975). Depletion was determined as total silica (soluble plus biogenic) to correct for increases or losses of biogenic silica in the trophogenic zone. Therefore, the equation for silica depletion at any given depth is

$$
\mathrm{DEP}=\frac{\left(\mathrm{SRS}_{1}+\mathrm{BSI}_{1}\right)-\left(\mathrm{SRS}_{2}+\mathrm{BSI}_{2}\right)}{t_{2}-t_{1}}
$$

where DEP equals silica depletion or disappearance in $\mathrm{g} \cdot \mathrm{m}^{-3} \cdot \mathrm{d}^{-1}$, SRS equals soluble reactive silica in $\mathrm{g} \cdot \mathrm{m}^{-3}$, BSI equals biogenic silica in $\mathrm{g} \cdot \mathrm{m}^{-3}$, and $t_{1}$ and $t_{2}$ are Julian dates. Depletion rates were integrated for different depth intervals to obtain flux rates of biogenic silica on an areal basis.

Soluble silica was determined colorimetrically with the heteropoly blue method on a Technicon AutoAnalyzer II. Biogenic silica was determined on samples from 1979 that were collected on Nuclepore filters $(0.4$ $\mu \mathrm{m}$ ), digested with $0.2 \mathrm{~N} \mathrm{NaOH}$ for $10 \mathrm{~min}$ at $100^{\circ} \mathrm{C}$ (Paasche 1973), and then mea- sured colorimetrically by the heteropoly blue method. Samples from 1976 were collected on Millipore filters $(0.45 \mu \mathrm{m})$ and then digested with a $\mathrm{HNO}_{3}-\mathrm{HF}$ reagent and neutralized with boric acid. Particulate silica concentrations were then determined by atomic absorption spectrometry using a nitrous oxide flame (Simmons 1980). Mineral silicates are leached slowly during sodium hydroxide or sodium carbonate digestion (Krausse et al. 1983), but would be completely dissolved with hydrofluoric acid. Values for particulate silica in the 1976 samples digested with hydrofluoric acid therefore probably include some contribution from mineral silicates. For the samples of the offshore upper water column used to calculate biogenic silica fluxes in this paper, errors resulting from inclusion of mineral silicates would be small (probably $<10 \%$ ); they would be greater for nearshore and nearbottom samples, which include a greater proportion of silica minerals (Schelske et al. 1983; Chambers and Eadie 1981).

Predicted fluxes-Silica fluxes can be predicted from the silica depletion model of Schelske (1975) if it is assumed that the flux of biogenic silica is equivalent to the disappearance of total silica (biogenic plus soluble) in the water column. These predicted fluxes were calculated with the equation

$$
F=\frac{Z_{m}\left(C_{w m}-C_{s c}\right)+Z_{t}\left(C_{s c}-C_{s m}\right)}{t_{2}-t_{1}}
$$

where $F$ is flux in $\mathrm{g} \cdot \mathrm{m}^{-2} \cdot \mathrm{d}^{-1}, Z_{m}$ is station depth in $\mathrm{m}$, and $Z_{t}$ is depth of summer trophogenic zone in $\mathrm{m} ; C_{w m}$ is winter maximum concentration, $C_{s c}$ is minimum spring circulation concentration, and $C_{s m}$ is minimum summer stratification concentration in $\mathrm{g} \cdot \mathrm{m}^{-3} ; t_{1}$ is Julian date when $C_{w m}$ is present and $t_{2}$ is that when $C_{s m}$ is present.

\section{Results}

Sediment trap fluxes - In 1978 biogenic silica fluxes changed seasonally, and daily flux rates decreased progressively during the period of collections. At all stations rates were highest from April to June at the beginning of the study and lowest from late October to mid-November at the end of the study (Fig. 2). Measured fluxes of biogenic silica in near-bottom samples, especially at 

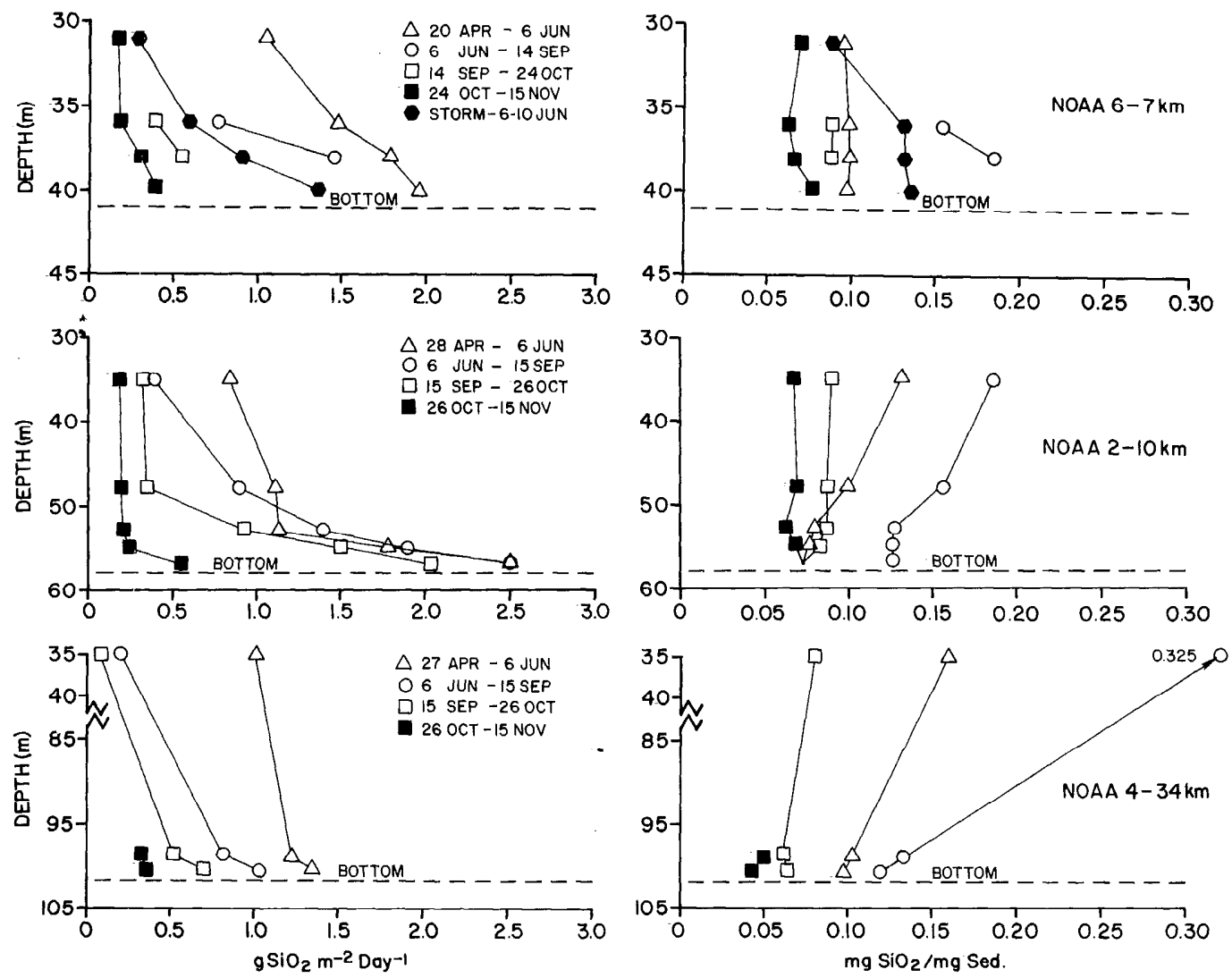

Fig. 2. Daily flux rates and fractions of biogenic silica in 1978 sediment trap collections by depth and station. Traps at NOAA 6 were retrieved after 4 days of placement in June to record the effects of a storm event.

NOAA 2, were greater than at shallower depths in the water column. Chambers and Eadie (1981) also found greater mass particle fluxes in near-bottom samples which they attributed to downslope transport and resuspension of local sediments. The fraction of biogenic silica in sedimented material also varied seasonally and was greater in collections made in late April to early June and early June to mid-September than in the two collections later in the year (Fig. 2).

The fraction of sedimented material that was biogenic silica varied less with depth than the flux of biogenic silica. In fact, except for the storm period (NOAA 6), the fraction of biogenic silica in profiles for different collection periods was either uniform with depth or decreased with depth (Fig. 2). These results show, particularly at the nearshore stations NOAA 2 and NOAA 6, that the proportion of biogenic silica in resuspended sediments decreased with depth or that resuspended materials contained a smaller proportion of biogenic silica than the material being sedimented.

The 1980-1981 sediment traps were set in offshore waters in June and were sampled

Fig. 3. Measurcd fluxes and fractions of biogenic silica in 1980-1981 sediment trap collections by depth and station. Fluxes are for the time interval given for each station. Dotted lines are predicted fluxes by depth interval calculated according to Eq. 1. 

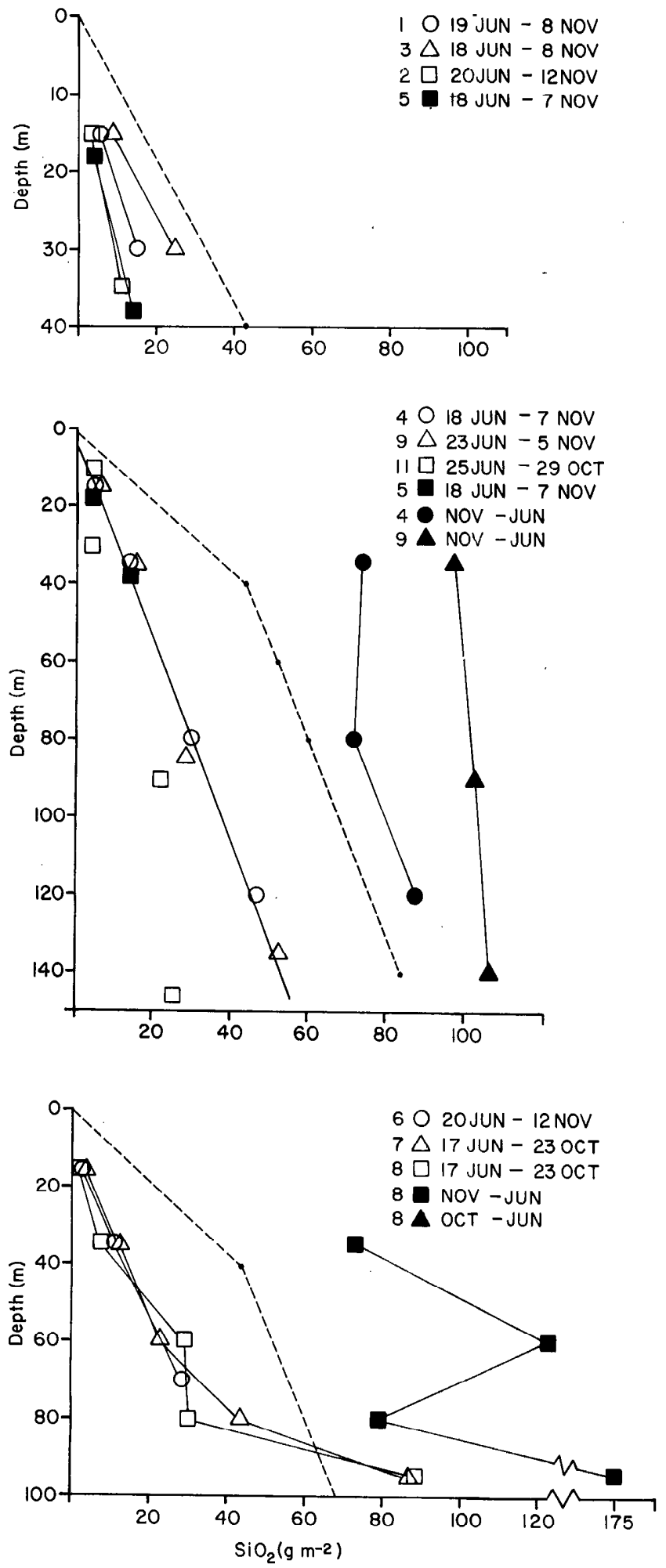
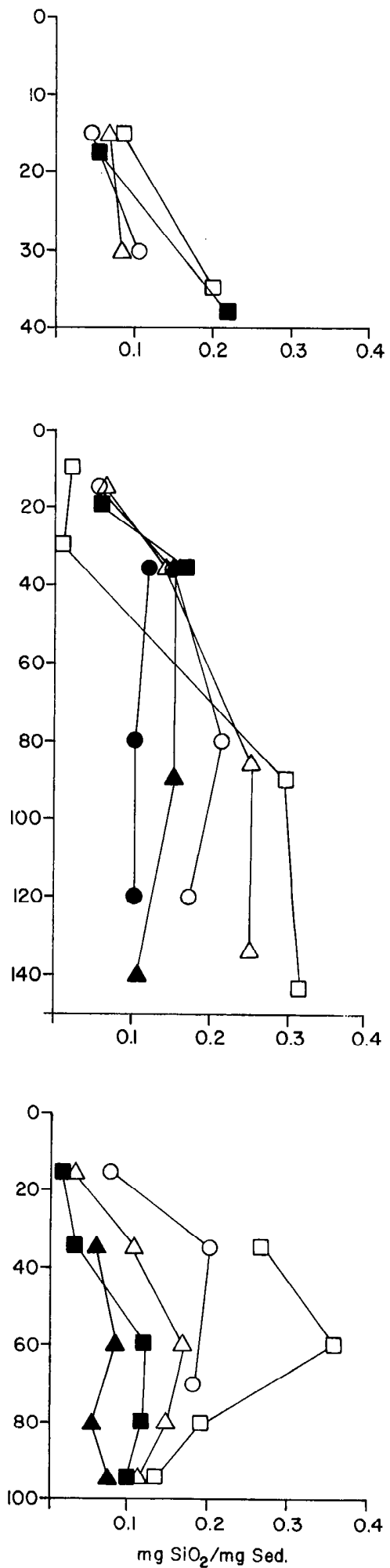
Table 1. Water-column biogenic silica fluxes based on silica disappearance at different stations in Lake Michigan. Data are in $\mathrm{g} \mathrm{SiO}_{2} \cdot \mathrm{m}^{-2}$ for the period specified (N.D. - not determined).

\begin{tabular}{|c|c|c|c|c|c|}
\hline Station & Year & $\begin{array}{c}\text { Station } \\
\text { depth (m) }\end{array}$ & $\begin{array}{l}24 \mathrm{Apr}- \\
5 \mathrm{Jun}\end{array}$ & $\begin{array}{l}5 \text { Jun- } \\
15 \text { Aug }\end{array}$ & Total \\
\hline NLM 06* & 1976 & 182 & -1.3 & 30 & 29 \\
\hline NLM 17 & 1976 & 274 & 13 & 23 & 36 \\
\hline NLM 25 & 1976 & 198 & 3.1 & 27 & 30 \\
\hline NLM 36 & 1976 & 105 & 15 & 18 & 33 \\
\hline SRP 02† & 1979 & 178 & N.D. & 34 & 34 \\
\hline ANL $5 \ddagger$ & 1975 & 67 & 25 & 3.0 & 28 \\
\hline \multicolumn{6}{|l|}{ NLM avg, } \\
\hline 20 stations & & & & & 26 \\
\hline Predicted (strati- & & & & & \\
\hline fied period) & & & - & - & 36 \\
\hline
\end{tabular}

* NLM data from Schelske et al. 1983.

$\dagger$ Data from Fig. 4.

$\$$ Calculated from data of Conway et al. 1977

only twice, once in November and then in the following June, giving a summer-fall and a winter-spring series of data. These traps were generally set far enough above the bottom to avoid significant resuspension effects. However, at four of the stations in the southern part of the lake (stations 1, 2,3 , and 5) no traps were set below $40 \mathrm{~m}$ (Fig. 3), and data for the winter-spring series are available only for three stations $(4$, 8 , and 9).

Patterns of fluxes for the two time periods were very different. In the winter-spring period, all fluxes were greater than predicted by the silica depletion model (see Fig. 3), whcreas all but two summer-fall fluxcs were less than predicted by the model. The exceptions were traps at $95 \mathrm{~m}(5 \mathrm{~m}$ above the bottom) at stations 7 and 8 where the flux apparently was increased by resuspension. Average daily biogenic silica fluxes in the winter-spring period were larger at comparable depths than in the summer-fall period. In the winter-spring sampling, the fraction of biogenic silica in sedimented material was essentially constant with depth; in the summer-fall period, the fraction increased with depth down to $35-40 \mathrm{~m}$ and then appeared to stay constant (Fig. 3).

Calculated fluxes-Calculated fluxes varied little among the six stations, ranging only from 28 to $36 \mathrm{~g} \mathrm{SiO}_{2} \cdot \mathrm{m}^{-2}$, for the period late April to mid-August. These fluxes agreed well with predicted fluxes for the thermally stratified period (Table 1).

Although calculated fluxes varied little among stations, there was a difference in seasonal phasing of silica depletion in the water column among the stations, which can be related to water depth and onset of thermal stratification. ANL 5 was the only station in the southern basin, and it was thermally stratified with a surface temperature of $13^{\circ} \mathrm{C}$ and depleted in epilimnetic silica by early June (fig. 2: Conway et al. 1977). At ANL 5, 89\% of the silica depletion occurred between early April and early June. The relatively large depletion at NLM 36, a shallow station, can also be attributed to early thermal stratification. In June, the surface temperature $\left(9^{\circ} \mathrm{C}\right)$ at NLM 36 was higher and surface silica depleted more than at other NLM stations. The large apparent depletion at NLM 17 by early June may have resulted from an overestimation of soluble silica in April or to sampling of different water masses (Schelske et al. 1983).

Predicted fluxes-Fluxes of biogenic silica were estimated from Eq. 2 on the basis of four assumptions about the annual silica cycle: that the winter maximum concentration was $1.4 \mathrm{mg} \cdot$ liter $^{-1}$; that $0.4 \mathrm{mg} \cdot$ liter $^{-1}$ of silica was utilized in the water column for diatom growth during the thermally mixed period in the spring; that the average trophogenic concentration decreased from 1.0 to $0.1 \mathrm{mg} \cdot$ liter $^{-1}$ during summer stratification; and that the summer trophogenic zone was $40 \mathrm{~m}$ deep. The assumption that the winter maximum concentration was 1.4 $\mathrm{mg} \cdot$ liter $^{-1}$ is reasonable based on values obtained from winter sampling by Rousar 
(1973) and other data discussed by Schelske et al. (1980, p. 153, 157). An average silica concentration of $1.0 \mathrm{mg} \cdot \mathrm{liter}^{-1}$ at the end of the thermally mixed period appears to be reasonable for the northern part of Lake Michigan based on data from Rousar (1973) and Schelske et al. (1983). In addition, data for station SRP 02 in Fig. 4 show a reduction of total silica equivalent to $0.9 \mathrm{mg}$. liter $^{-1}$ from June to August; the thermally mixed period of SRP 02 was just completed when sampling was initiated in June. The assumption that the minimum concentrations of silica in the summer epilimnion was $0.1 \mathrm{mg} \cdot \operatorname{liter}^{-1}$ is supported by data from several studies reviewed by Schelske et al. (1980).

Data to support the fourth assumption are limited but data on depth of silica utilization in Fig. 4 and those of Conway et al. (1977), Schelske et al. (1983), and Bartone and Schelske (1982) indicate that $30-40 \mathrm{~m}$ is a good estimate of the range. Data in Fig. 4 also show that metalimnetic disappearance below the $20-\mathrm{m}$ epilimnion accounts for a considerable fraction of the silica depletion from July to August. Decpening of the epilimnion and additional utilization of metalimnetic silica throughout September could be used as arguments for an average utilization of $0.9 \mathrm{mg} \cdot$ liter $^{-1}$ over a $40-\mathrm{m}$ depth during the thermally stratified period.

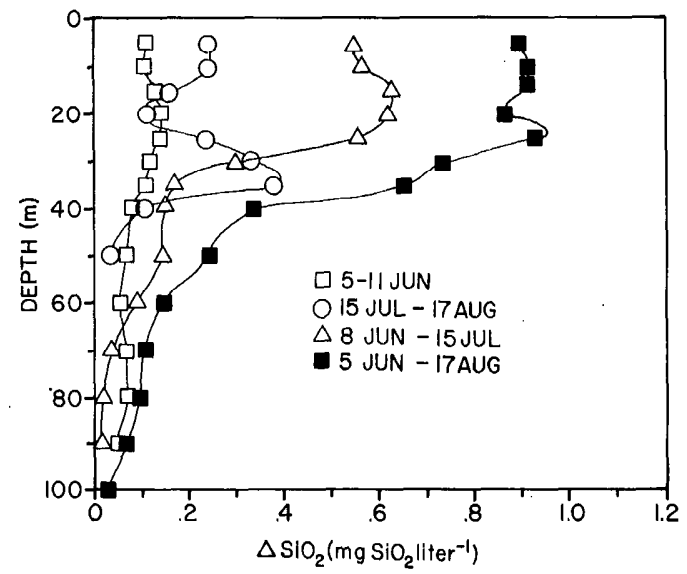

Fig. 4. Disappearance of total silica at SRP 02, Grand Traverse Bay, Lake Michigan, for several time intervals from 5 June-17 August 1979. Results are calculated according to Eq. 1. Samples were collected at depth intervals of 5 or $10 \mathrm{~m}$. Data for 15 July and 17 August represent averages of several profiles taken over a 5- or 6-day period. The water column was wcakly stratified by 11 June when the temperature at $2 \mathrm{~m}$ was $9.0^{\circ} \mathrm{C}$.

\section{Discussion}

Biogenic silica fluxes calculatcd from silica disappearance are in very good agreement with predicted fluxes for the summer stratificd period (Table 1). These estimates of disappearance for individual stations ranged from 28 to $36 \mathrm{~g} \cdot \mathrm{m}^{-2}$ for the ther-

Table 2. Biogenic silica fluxes obtained from scdiment trap collections for four time periods during 1978. Total measured fluxes for each station are compared to predicted fluxes. Data are in $\mathrm{g} \mathrm{SiO}_{2} \cdot \mathrm{m}^{-2}$ for the period specified. Dashes indicate missing samples.

\begin{tabular}{|c|c|c|c|c|c|c|c|c|}
\hline $\begin{array}{l}\text { NOAA } \\
\text { station } \\
\text { No. }\end{array}$ & $\begin{array}{c}\text { Station } \\
\text { depth (m) }\end{array}$ & $\begin{array}{c}\text { Trap } \\
\text { depth (m) }\end{array}$ & $\begin{array}{l}28 \text { Apr- } \\
6 \text { Jun }\end{array}$ & $\begin{array}{l}6 \mathrm{Jun}- \\
15 \mathrm{Sep}\end{array}$ & $\begin{array}{l}15 \mathrm{Scp}- \\
26 \mathrm{Oct}\end{array}$ & $\begin{array}{l}26 \mathrm{Oct-} \\
15 \mathrm{Nov}\end{array}$ & $\begin{array}{c}\text { Total } \\
\text { (measured) }\end{array}$ & $\begin{array}{c}\text { Predicted } \\
\text { (model) }\end{array}$ \\
\hline \multicolumn{9}{|c|}{ Offshore stations } \\
\hline 4 & 102 & 35 & 40 & 20 & 3.7 & - & 64 & 77 \\
\hline 8 & 101 & 35 & 27 & - & - & _ & & \\
\hline 8 & 101 & 91 & 40 & 33 & & 3.6 & 77 & 76 \\
\hline \multicolumn{9}{|c|}{ Base of slope stations } \\
\hline 3 & 83 & 35 & 42 & - & - & - & & \\
\hline & & 73 & 49 & - & 36 & - & & \\
\hline 7 & 87 & 77 & 47 & - & - & 4.0 & & \\
\hline \multicolumn{9}{|c|}{ Midslope stations } \\
\hline \multirow[t]{3}{*}{2} & 58 & 35 & 33 & 39 & 14 & 3.8 & 90 & 59 \\
\hline & & 35 & 34 & 39 & 15 & 4.2 & 92 & 59 \\
\hline & & 48 & 43 & 76 & 14 & 4.2 & 137 & 59 \\
\hline \multirow[t]{2}{*}{6} & 41 & 31 & 41 & - & - & 3.7 & & \\
\hline & & 36 & 47 & 75 & 15 & 4.0 & 141 & 52 \\
\hline
\end{tabular}


mally stratified period compared to the predicted value of $36 \mathrm{~g} \cdot \mathrm{m}^{-2}$. The two types of estimate should agree closely because both are calculated from the same set of environmental factors. The critical factors in the estimates are concentration of total silica at the onset of thermal stratification and depth of silica utilization by diatoms (see Eq. 2).

Unlike the calculated fluxes (Table 1), biogenic silica fluxes from the 1978 sediment trap collections covered a wide rangc (Table 2), and predicted fluxes agreed only with those from the offshore stations. Biogenic silica fluxes from sediment traps at the midslope stations were 2-3 times those predicted by the model.

Sediment trap fluxes at the two midslope stations that were greater than model predictions (Table 2) can be attributed to factors that distinguish these stations from those farther offshore. First, both stations are $<10 \mathrm{~km}$ from the mouth of the Grand River, which carries relatively high concentrations of diatoms (biogenic silica) and total silica (Schelske et al. 1980). This supply of total silica could be transported offshore and increase the biogenic silica flux. Second, the water is shallow so that silica recycled in the bottom waters or sediments could be diffused and advected into the upper waters all summer and result in greater diatom production than predicted by the model. The flux at NOAA 6 (7 km offshore) was greater than that at NOAA $2(10 \mathrm{~km}$ offshore), which would be expected if tributary loading and recycled silica were important. Third, the midslope stations are at the edge of the 10$\mathrm{km}$ wide nearshore zone (as defined by Mortimer 1975) where the main transfer of energy from the wind to water movements occurs. This can resuspend sedimented materials and also increase the flux of nutrients from sediments to overlying waters. Fourth, upwelling occurs frequently in the nearshore zone (Mortimer 1975) and contributes silica-rich water to the trophogenic zone which promotes diatom growth (Schelske et al. 1971). Some combination of these factors could supply new silica to the nearshore zone and increase diatom production over that in offshore waters.

The contribution of soluble and biogenic silica loading from tributaries to the poten- tial biogenic silica flux can be evaluated from a calculation of tributary loading. Parker et al. (1977) cited an average tributary load of $11 \times 10^{10} \mathrm{~g} \mathrm{SiO}_{2} \cdot \mathrm{yr}^{-1}$ or an average silica concentration of $4.0 \mathrm{mg} \mathrm{SiO}{ }_{2} \cdot$ liter $^{-1}$. If this load were utilized in diatom production, it would provide an average biogenic silica flux of $16 \mathrm{~g} \cdot \mathrm{m}^{-2} \cdot \mathrm{yr}^{-1}$ over the nearshore area of the lake if that is assumed to be $20 \%$ of the lake area. Somewhat larger fluxes would be expected in the vicinity of the sediment trap sites because the Grand River and several other large tributaries with greater than average diatom populations drain into the southeastern part of the lake (Schelske et al. 1980). In fact, tributaries along this $130 \mathrm{~km}$ of shoreline between Muskegon and St. Joseph account for more than a third of the lake's average historical hydraulic loading of $1,064 \mathrm{~m}^{3} \cdot \mathrm{s}^{-1}$ (Sonzogni et al. 1978). Therefore, the potential flux of biogenic silica of tributary origin at the midslope trap stations could be severalfold the calculated nearshore average of $16 \mathrm{~g} \cdot \mathrm{m}^{-2} \cdot \mathrm{yr}^{-1}$.

The contribution of soluble silica released from nearshore sediments in the area near the Grand River appears to be comparable to that from tributary loading. It should be obvious, however, that some of the silica released from sediments in the nearshore must be attributed to tributary loading, nearshore diatom production, and subsequent sedimentation of diatoms. Measured release rates of soluble silica from sediments averaged $59 \mathrm{~g} \cdot \mathrm{m}^{-2} \cdot \mathrm{yr}^{-1}$ for samples collected near Grand Haven (M. Quigley pers. comm.). Quigley's average daily rate equals $0.16 \mathrm{~g} \cdot \mathrm{m}^{-2} \cdot \mathrm{d}^{-1}$, or about $24 \mathrm{~g} \cdot \mathrm{m}^{-2}$ for the period in 1978 when our sediment traps were in place. Quigley's experiments were run at $12^{\circ} \mathrm{C}$, and rates may have been higher during the warmer months of the year when the sediment traps were in place.

The combined increases in biogenic silica flux $\left(40-72 \mathrm{~g} \cdot \mathrm{m}^{-2}\right)$ that can be attributed to tributary loading $\left(16-48 \mathrm{~g} \cdot \mathrm{m}^{-2}\right)$ and sediment release $\left(24 \mathrm{~g} \cdot \mathrm{m}^{-2}\right)$ of silica in the nearshore compensate for the greater than expected biogenic silica fluxes obtained from sediment trap collections at the midslope stations (Table 2). Silica fluxes at the midslope stations were greater from June to November, during the period of thermal strat- 
ification, than at the profundal stations. These data show that new silica is supplied at a much greater rate to the trophogenic zone in the nearshore than in the offshore waters of the lake.

Higher than predicted fluxes of biogenic silica at midslope or nearshore stations (Table 2) might also be expected on the basis of known differences in primary production between offshore and nearshore waters. Fee (1973) found that primary production rates were about twice as large in the nearshore as the average of $130 \mathrm{~g} \mathrm{C} \cdot \mathrm{m}^{-2} \cdot \mathrm{yr}^{-1}$ in offshore waters. Parker et al. (1977) estimated annual primary production of $100 \mathrm{~g} \mathrm{C} \cdot \mathrm{m}^{-2}$. $\mathrm{yr}^{-1}$ at ANL 5, which is representative of Fee's offshore rate, and an annual silica requirement for offshore diatom production of $114 \mathrm{~g} \mathrm{SiO}{ }^{2} \cdot \mathrm{m}^{-2} \cdot \mathrm{yr}^{-1}$. We calculated a biogenic silica flux at ANL 5 of $110 \mathrm{~g} \mathrm{SiO}_{2}$. $\mathrm{m}^{-2}$ from 9 May-6 November (Table 3) from sediment trap data presented by Parker et al. (1977). This measured biogenic silica flux at $37 \mathrm{~m}$ is nearly twice as large as would be predicted from Eq. 2 and confirms our hypothesis that diatom production and measurcd biogenic silica flux in the nearshore were dependent to a significant extent on new silica.

Whether resuspension contributes significantly to increased nearshore biogenic silica fluxes should be considered in greater detail. Chambers and Eadie (1981) found that the mass particle flux increased exponentially from about $10 \mathrm{~m}$ above bottom to $1 \mathrm{~m}$ above bottom at the 1978 stations. Bloesch (1982) found that organic matter was resuspended more frequently in the nearshore than in the offshore waters of Lake Erie. Pennington (1974) found that resuspension effects were greater in shallow, small lakes than in deep, small lakes. These results argue that resuspension effects could contribute to the increased flux of biogenic silica at nearshore stations. However, surficial sediments contain proportionately less biogenic silica than materials that are sedimenting through the water column. At ANL 5, which would have sediments with a greater biogenic silica content than coarsergrained sediments closer to shore, the biogenic silica content of surficial sediments was only $0.04 \mathrm{mg} \mathrm{SiO}{ }_{2} \cdot \mathrm{mg}^{-1}$ sediment (Par-
Table 3. Biogenic silica fluxes in 1975 at ANL 5 calculated from data in table 2 and fig. 5 of Parker et al. (1977).

\begin{tabular}{ccc}
\hline & \multicolumn{2}{c}{$\begin{array}{c}\text { Biogenic silica fluxes } \\
\left(\mathrm{g} \mathrm{SiO}_{2} \cdot \mathrm{m}^{-2}\right)\end{array}$} \\
\cline { 2 - 3 } Period & $37 \mathrm{~m}$ & $60 \mathrm{~m}$ \\
\hline 9 May-5 Jun & 29 & 40 \\
5 Jun-8 Jul & 19 & 63 \\
8 Jul-5 Aug & 21 & 57 \\
5 Aug-5 Sep & 12 & 20 \\
5 Sep-7 Oct & 16 & 34 \\
7 Oct-6 Nov & 12 & 42 \\
Total & 109 & 256 \\
\hline
\end{tabular}

ker et al. 1977). This amount of biogenic silica is much less than that of sedimenting materials collected from April to September (Fig. 2) when the major portion of the biogenic silica flux was collected in sediment traps. It is possible that suspended material in the nepheloid layer might contain larger concentrations of biogenic silica; however, our data (Schelske et al. 1983) show that soluble silica concentrations in the nepheloid layer are generally greater than biogenic silica concentrations. Therefore, resuspension of the nepheloid layer would in cffect be contributing recycled or new silica for diatom production.

The data on measured biogenic silica fluxes in Table 2 were taken from sediment traps set at depths where resuspension would be negligible or minimized. Obviously biogenic silica fluxes would have been greater if data from near-bottom traps had bcen used (see Fig. 2). Sediment trap data obtained monthly in 1975 by Parker et al. (1977) are better suited than ours to show seasonal effects of resuspension on measured fluxes of biogenic silica. Their results (Table 3) show that fluxes at $60 \mathrm{~m}$ were nearly 2.5 times those at $37 \mathrm{~m}$ at a station located in $67 \mathrm{~m}$ of water. Even greater differences in fluxes resulting from resuspension would undoubtedly have been obtained if traps had becn set below $60 \mathrm{~m}$. Greater fluxes resulting directly from diatom production also would have been expected if traps had been set at $40-50 \mathrm{~m}$, because $37 \mathrm{~m}$ may be in the lower part of the trophogenic zone (see Fig. 4).

Fluxes of biogenic silica calculated either indirectly from disappearance or directly 
from 1978 sediment trap collections varied seasonally. Fluxes were greatest from AprilJune for the 1978 sediment trap collections (Table 2) and during June-July for the disappearance calculated from water chemistry (Fig. 4). Fluxes would be expected to decrease after July when epilimnetic silica concentrations approach levels that are limiting for diatom growth (Schelske and Stoermer 1971), and this pattern is evident from the disappearance of total silica from the water column (Fig. 4) and sediment trap data (Table 3). The results from the 1980 summer-fall sediment traps also show a seasonal pattern in that a large fraction of the biogenic silica produced by diatoms had been sedimented out of the water column by the time traps were placed in the lake during the third week of June (Fig. 3). However, the fraction of biogenic silica in sedimented material was greatest during JuneSeptember and not during the period of greatest silica flux (Fig. 2). Apparently a large fraction of the material sedimented during April-June was inorganic materials that are suspended during winter circulation and thermally mixed periods in spring. Parker et al. (1977) found that the fraction of biogenic silica in monthly sediment trap samples decreased from $31 \%$ in May to $6 \%$ in October, and then increased slightly in November.

Biogenic silica fluxes during summer-fall 1980 varied greatly among stations even though these stations were located in offshore waters. At the deepest midlake stations, the flux was less at station 11 in the northern part of the lake than at either station 4 or 9 in the southern part. Lower primary production in the northern part of the lake (Rodgers and Salisbury 1981) may explain some of the difference, but both basins are silica limited (Schelske et al. 1980). Sedimentation varies greatly over the lake (Cahill 1981) and physical factors, particularly resuspension and subsurface circulation patterns, may affect patterns of biogenic silica sedimentation. The measured biogenic silica flux in the summer-fall period at station 3 on the eastern side of the lake was greater than that at stations 1 and 2 on the western side of the lake. Station 3 is roughly $20 \mathrm{~km}$ offshore from the mouth of the St.
Joseph River. This location near a major river and a source of new silica, or the fact that sedimentation rates are higher on the eastern side of the lake (Cahill 1981), may account for the differences among these southern stations.

However, not enough sediment traps have been used so far to determine how biogenic silica fluxes vary spatially. Because the trap studies were not designed to measure biogenic silica fluxes from the trophogenic zone of Lake Michigan, traps were not set at ideal depths nor for time periods most suitable for this purpose. Data on silica disappearance (Fig. 4) show that traps at depths ranging from 40-60 $\mathrm{m}$ would collect most of the biogenic silica production during the thermally stratified period. Timing of collections is also important because, until the water column is stratified, part of the measured flux at any depth will be the result of turbulence and convective mixing which accounts for the large winter-spring fluxes (see Fig. 3). If traps are set soon after the lake is stratified, then the suspended biogenic silica found during the winter circulation period will be collected in the traps as it is sedimented in the stratified water column. Some of this suspended biogenic silica originates from the nepheloid and benthic boundary layers and would contain diatoms that were produced in previous years.

For accurate estimates of annual flux rates of biogenic silica, the amount or fraction of biogenic silica that is resuspended during winter circulation must be known. We have not tried to calculate annual flux rates here because limited winter-spring data were collected and therefore have limited our estimates mainly to the thermally stratified pcriod. Annual flux rates of biogenic silica could be predicted if data on concentrations of soluble and biogenic silica were collected simultaneously with sediment trap studies.

The close agreement between predicted and measured fluxes of biogenic silica suggests that only a small fraction of the production is dissolved in the water. If a large fraction of biogenic silica wcre dissolving, the flux collected in sediment traps should decrease with depth. However, measured fluxes of biogenic silica in sediment traps either increase with depth in the spring- 
summer samples (Fig. 3) which has been attributed to time of trap placement, or remain constant with depth during stratification when resuspension effects can be ruled out (Fig. 2). These results indicate that most biogenic silica is dissolved in either the sediments or the nepheloid layer.

Low rates of dissolution in the water can be inferred from our data and other unpublished data on Lake Michigan. At SRP 02, there were no measurable increases in silica concentration at $100 \mathrm{~m}$ (see Fig. 4) and deeper during thermal stratification. A similar pattern was found at deep northern Lake Michigan stations (Bartone and Schelske 1982). However, increases in soluble silica were found during thermal stratification in the nepheloid layer at these stations. Transport of biogenic silica to depths of $100 \mathrm{~m}$ or more with little dissolution also suggests that a large fraction of the transport is mediated by grazing of zooplankton and rapid settling of fecal pellets. Our data also suggest, although it was not measured directly, that silica recycling in the euphotic zone was minimal. Paasche and Ostergren (1980) found that biogenic silica was lost rapidly from the euphotic zonc of Oslofjord. Stable isotope techniques have also been used to measure dissolution (recycling) rates of biogenic silica in oceanic systems. Nelson and Gordon (1982) found that rates of dissolution in the Antarctic Circumpolar Current ranged from 5 to $20 \%$ in the upper $20 \mathrm{~m}$ and averaged $32 \%$ in the $100-\mathrm{m}$ photic zone, in contrast to an upwelling region where the rate of dissolution in the euphotic zone was sufficient to supply silica uptake by phytoplankton (Nelson and Goering 1977). The Lake Michigan system therefore appears to be similar to the cold Southern Ocean.

The fact that biogenic silica fluxes obtained from sediment traps at offshore stations were essentially the same as those predicted on the basis of expected silica depletion in the water column is important because it shows that biogenic silica fluxes were directly related to the autotrophic production of diatoms in the cuphotic zone. Reynolds and Wiseman (1982) also found that biogenic silica fluxes (obtained from diatom counts and silica content) were equal to the uptake of silica from the water. Mea- sured and predicted fluxes of biogenic silica, therefore, could be used to evaluate the efficiency of sediment trap collection. Efficiency of sediment trap collection has been estimated by comparing the capture and retention of unsupported ${ }^{210} \mathrm{~Pb}$ in sediment traps with the steady state accumulation rate of unsupported ${ }^{210} \mathrm{~Pb}$ in sediments (Lorenzen et al. 1981). Sediment trap studies could also be designed to study the importance of new and recycled silica in diatom production.

\section{References}

Bartone, C. R., And C. L. Schelske. 1982. Lakewide seasonal changes in limnological conditions in Lake Michigan in 1976. J. Great Lakes Res. 8: 413-427.

BLOESCH, J. 1982. Inshore-offshore sedimentation differences resulting from resuspension in the eastern basin of Lake Erie. Can. J. Fish. Aquat. Sci. 39: 748-759.

Canlll, R. A. 1981. Geochemistry of recent Lake Michigan sediments. Illinois State Gcol. Surv. Circ. 517. 94 p.

Chambers, R. L., And B. J. Eadie. 1981. Nepheloid and suspended particulate matter in south-eastern Lake Michigan. Sedimentology 28: 439-447.

Conway, H. L., J. I. Parker, E. M. Yaguchi, AND D. L. Mellinger. 1977. Biological utilization and regeneration of silicon in Lake Michigan. J. Fish. Res. Bd. Can. 34: 537-544.

DeMASTER, D. J. 1981. The supply and accumulation of silica in the marine environment. Gcochim. Cosmochim. Acta 45: 1715-1732.

Dugdale, R. C., AND J. J. Goering. 1967. Uptake of new and regenerated forms of nitrogen in primary productivity. Limnol. Oceanogr. 12: 196206.

FEE, E. J. 1973. A numerical model for determining integral primary production and its application to Lake Michigan. J. Fish. Res. Bd. Can. 30: $1447-$ 1468.

GARDNER, W. D. 1980a. Sediment trap dynamics and calibration: A laboratory evaluation. J. Mar. Res. 38: $17-39$.

. 1980h. Field assessment of sediment traps. J. Mar. Res. 38: 41-52.

Hargrave, B. T., and N. M. Burns. 1979. Assessment of sediment trap collection efficiency. Limnol. Oceanogr. 24: 1124-1136.

Krausse, G. L., C. L. Scheiske, and C. O. Davis. 1983. Comparison of three wet-alkaline methods of digestion of biogenic silica in water. Freshwater Biol. 13: 73-81.

Lorenzen, C. J., F. R. Suuman, AND J. T. BenNett. 1981. In situ calibration of a scdiment trap. Limnol. Oceanogr. 26: 580-585.

Mortimer, C. H. 1975. Physical characteristics of Lake Michigan and its responses to applied forces, p. 13-102. In Environmental status of the Lake 
Michigan region, v. 2. Argonne Natl. Lab. ANL/ ES-40.

Nel.Son, D. M., AND J. J. Goering. 1977. Near-surface silica dissolution in the upwelling region off northwest Africa. Deep-Sea Res. 24: 65-73.

- AND L. I. GoRDON. 1982. Production and pelagic dissolution of biogenic silica in the Southern Ocean. Geochim. Cosmochim. Acta 46: 491501.

PAASCHE, E. 1973. Silicon and the ecology of marine plankton diatoms. 1. Thalassiosira pseudonana (Cyclotella nana) grown in a chemostat with silicate as limiting nutrient. Mar. Biol. 19: 117-126.

- AND I. OSTERGREN. 1980. The annual cycle of plankton diatom growth and silica production in the inner Oslofjord. Limnol. Oceanogr. 25: 481494.

Parker, J. I., H. L. Conway, and E. M. Yaguchi. 1977. Dissolution of diatom frustules and recycling of amorphous silicon in Lake Michigan. J. Fish. Res. Bd. Can. 34: 545-551.

Pennington, W. 1974. Seston and sediment formation in five Lake District lakes. J. Ecol. 62: 215251.

REYNOLDS, C. S., AND S. W. WISEMAN. 1982. Sinking losses of phytoplankton in closed limnetic systems. J. Plankton Res. 4: 489-522.

Rodgers, P. W., AND D. K. Salisbury. 1981. Water quality modeling of Lake Michigan and consideration of the anomalous ice cover of 1976-1977. J. Great Lakes Res. 7: 467-480.

RousAR, D. C. 1973. Seasonal and spatial changes in primary production and nutrients in Lake Michigan. Water Air Soil Pollut. 2: 497-514.

SCHELSKE, C. L. 1975. Silica and nitrate depletion as related to rate of eutrophication in Lakes Michigan, Huron, and Superior, p. 277-298. In A. D. Hasler [ed.], Coupling of land and water systems. Springer.

$\longrightarrow$, L. E. FeldT, ANd M. S. Simmons. 1980. Phytoplankton and physical-chemical conditions in selected rivers and the coastal zone of Lake Michigan, 1972. Univ. Mich. Great Lakes Res. Div. Publ. 19. 162 p.

, R. A. Moll, And T. D. Berry. 1983. The limnology and phytoplankton of northern Lake Michigan. Part 1. Limnological characteristics. Univ. Mich. Great Lakes Res. Div. Spec. Rep. 95. -, AND E. F. STOERMER. 1971. Eutrophication, silica depletion, and predicted changes in algal quality in Lake Michigan. Science 173: 423-424. , - AND L. E. FeldT. 1971. Nutrients, phytoplankton productivity and species composition as influenced by upwelling in Lake Michigan. Proc. 14th Conf. Great Lakes Res., p. 102113.

Simmons, M. S. 1980. Routine determination of particulate silica in water. Anal. Lett. 13: 67-74.

Sonzogni, W. C., T. J. Monteith, W. N. Bach, And V. H. HuGHES. 1978. United States Great Lakes tributary loadings. Int. Ref. Group on Great Lakes Pollution from Land Use Activities. $187 \mathrm{p}$.

Wahlgren, M. A., AND D. M. Nelson. 1976. Factors affecting the collection efficiency of sediment traps in Lake Michigan, p. 103-106. In Radiol. Environ. Res. Div. Annu. Rep., Part 3. Argonne Natl. Lab. ANL-76-88.

Submitted: 15 November 1982 Accepted: 3 June 1983 